\title{
Multi-Sensors Remote Sensing Applications for Assessing, Monitoring, and Mapping NPK Content in Soil and Crops in African Agricultural Land
}

\author{
Khalil Misbah ${ }^{1, *(\mathbb{D})}$, Ahmed Laamrani ${ }^{1} \mathbb{D}$, Keltoum Khechba ${ }^{1}$, Driss Dhiba ${ }^{2} \mathbb{D}$ and Abdelghani Chehbouni ${ }^{1,2,3}(\mathbb{D}$ \\ 1 Center for Remote Sensing Applications (CRSA), Mohammed VI Polytechnic University(UM6P), \\ Ben Guerir 43150, Morocco; ahmed.laamrani@um6p.ma (A.L.); keltoum.khechba@um6p.ma (K.K.); \\ Abdelghani.chehbouni@um6p.ma (A.C.) \\ 2 International Water Research Institute, UM6P, Ben Guerir 43150, Morocco; driss.dhiba@um6p.ma \\ 3 Centre d'Études Spatiales de la Biosphère, Institut de Recherche pour le Développement (CESBIO/IRD), \\ CNES/CNRS/INRAE/UPS/Université de Toulouse, 31401 Toulouse, France \\ * Correspondence: khalil.misbah@um6p.ma; Tel.: +212-61-050-8917
}

Citation: Misbah, K.; Laamrani, A.; Khechba,K; Dhiba D.; Chehbouni, A. Multi-Sensors Remote Sensing

Applications for Assessing, Monitoring, and Mapping NPK Content in Soil and Crops in African Agricultural Land. Remote Sens. 2022, 14, 81. https://doi.org/10.3390/ rs14010081

Academic Editor: Giovanni Avola

Received: 1 December 2021

Accepted: 21 December 2021

Published: 24 December 2021

Publisher's Note: MDPI stays neutral with regard to jurisdictional claims in published maps and institutional affiliations.

Copyright: (c) 2021 by the authors. Licensee MDPI, Basel, Switzerland. This article is an open access article distributed under the terms and conditions of the Creative Commons Attribution (CC BY) license (https:// creativecommons.org/licenses/by/ $4.0 /)$

\begin{abstract}
Demand for agricultural products is increasing as population continues to grow in Africa. To attain a higher crop yield while preserving the environment, appropriate management of macronutrients (i.e., nitrogen $(\mathrm{N})$, phosphorus $(\mathrm{P})$ and potassium $(\mathrm{K}))$ and crops are of critical prominence. This paper aims to review the state of art of the use of remote sensing in soil agricultural applications, especially in monitoring NPK availability for widely grown crops in Africa. In this study, we conducted a substantial literature review of the use of airborne imaging technology (e.g., different platforms and sensors), methods available for processing and analyzing spectral information, and advances of these applications in farming practices by the African scientific community. Here we aimed to identify knowledge gaps in this field and challenges related to the acquisition, processing, and analysis of hyperspectral imagery for soil agriculture investigations. To do so, publications over the past 10 years (i.e., 2008-2021) in hyperspectral imaging technology and applications in monitoring macronutrients status for crops were reviewed. In this study, the imaging platforms and sensors, as well as the different methods of processing encountered across the literature, were investigated and their benefit for NPK assessment were highlighted. Furthermore, we identified and selected particular spectral regions, bands, or features that are most sensitive to describe NPK content (both in crop and soil) that allowed to characterize NPK. In this review, we proposed a hyperspectral data-based research protocol to quantify variability of NPK in soil and crop at the field scale for the sake of optimizing fertilizers application. We believe that this review will contribute promoting the adoption of hyperspectral technology (i.e., imaging and spectroscopy) for the optimization of soil NPK investigation, mapping, and monitoring in many African countries.
\end{abstract}

Keywords: hyperspectral imaging; agricultural soils; variable rate fertilization; fertigation; precision agriculture; machine learning; remote sensing; crop yield

\section{Introduction}

Modern agriculture faces the challenging issue of meeting global food demands of an increasing population while sustainably utilizing available resources [1]. In Africa, demand for agricultural products is increasing as population continues to grow in Africa [2]. To respond to such demand, nutrient availability can play a major role in increasing plant production and improve soil fertility for sustainable agricultural production. Macronutrients (i.e., nitrogen $(\mathrm{N})$, phosphorus $(\mathrm{P})$, potassium $(\mathrm{K})$, referred to hereafter as NPK) are one of the main farming inputs in plant production. [3]. Crops respond sensitively to the dosage of fertilizers, highlighting the importance of these in determining crop yield [4]. Insufficient doses can lead to low yield and quality of crop; whereas excessive application 
can lead to yield loss and negative environmental consequences [5]. Thus, obtaining and providing access to detailed in-field information can decrease input costs and increase yields while reducing the environmental footprint of fertilizers. One potential solution to optimize fertilizer application lies in providing farm operators with instantaneous and spatially distributed information on crops and soil [6]. Assessing and monitoring NPK in crops and soils are of great importance, so that appropriate and timely interventions can be made to adjust management practices and/or fertilization rate, and therefore help avoiding yield loss and potential negative environmental consequences, usually due the application of unspecified dosages. Soil NPK rates, a proxy for soil fertility [7], and their quantification is usually based on a conventional approach consisting of using punctual soil sampling and laboratory-based soil chemical analysis. However, these methods are proved to be costly and have limitation in time and space applications, especially if we plan to apply variable rate fertilization over large fields [8] and different time periods. Alternatively, previous studies have proven that multispectral and hyperspectral remote sensing datasets can be employed for successful determination and assessment of NPK. The following is an overview of these studies for NPK.

Nitrogen: based on the assumption which stipulates the existence of a strong correlation between $\mathrm{N}$ and some leaf traits, namely chlorophyll content [9], many studies have arisen, in which it is aimed to design remotely sensed approaches able to define the optimal $\mathrm{N}$ fertilizers recommendation for specific crops. In other words, the approach consisted of monitoring the variation of the spectral signature, as well as the sensitive bands (typically amid Red-edge and NIR wavelengths) to the photosynthetic pigment content in the crop in response to a variation of $\mathrm{N}$ fertilizers [10]. The critical importance of $\mathrm{N}$ to crop yield and photosynthesis makes it easier to highlight using biomass reflectance at specific wavelengths, compared to other nutrients. In fact, it is the main reason of the meteoric increase of the publications that treat the question of the optimization of $\mathrm{N}$ fertilizers for crops using remote sensing [11]. Besides studies that involved empirical regression on hyperspectral remote sensing data to quantify crop $\mathrm{N}$ content, other investigations assessed the outcomes of coupling and inversing state-of-art radiative transfer models, dedicated to characterizing spectral and directional reflectance of the vegetation cover type (i.e., PROSPECT, SAIL) [12]. Although being strongly impacted by the timing and availability of remote sensing data [13], this approach aimed to provide an indirect estimation of $\mathrm{N}$, that is ultimately retrieved from the crop leaf characteristics through the inversion of the corresponding radiative transfer modeling (RTM), taking pre-processed hyperspectral signals of the subject 's leaves as input [14]. The inversion algorithms are usually memory-hungry processes as they are based on concepts such as Look up tables [15]. Other studies assessed soil $\mathrm{N}$ content for the sake of digital soil mapping, which basically relies on remote sensing data as a complementary source of information due to its time and cost effectiveness, as opposed to the traditional approaches that rely heavily on the analysis of soil samples. In this context, the soil spectral signature in response to a variation of $\mathrm{N}$ content in soil samples is analyzed, with a consideration of the tradeoff between the spatial and spectral resolution. While some investigations examined direct soil reflectance at different wavelengths ranging in the NIR $(1100-2300 \mathrm{~nm}[16,17]$ and up to the MIR $(2500-25000 \mathrm{~nm})$ [18] to the variation of soil $\mathrm{N}$ content, others investigated the potential of spectral derivative of soil hyperspectral signature to draw insights about soil $\mathrm{N}$ status [8]. In the same scope, we find works that combined the high spectral resolution of Vis-NIR spectroscopy signal, with the high spatial resolution and coverage of satellite imagery to map the spatial variability of soil in N $[19,20]$.

Phosphorus: P concentration in soil plays a major role in soil fertility management [21]. In terms of variable rate fertilization implementation, the prediction of the spatial variability of $\mathrm{P}$ is more effective than monitoring its content in crops [22]. Rather, the attention of recent studies shifted into using remote sensing data. In fact, some have chosen the reflectance at specific wavelengths, or various indices approach (e.g., NDVI) based on hyperspectral response of soil, to indirectly predict total and extractable $\mathrm{P}$, assuming the 
relationship between the variability of soil $\mathrm{P}$ concentration with soil dynamic properties associated with mechanical factors (e.g., erosion) and chemical deposits (e.g., soil organic matter) [23-25]. Nevertheless, other investigations tried to monitor P deficiency within crops using hyperspectral reflectance, as a method to detect responses of crop next to a specific nutrient stress such that of phosphorus [26,27]. Multiple prediction models were deployed, as from the simple and interpretable models (e.g., PLSR, RF) [28-30], to the most black boxed deep learning algorithms (e.g.,NN, CNN) [31]. Among the studies that investigated the estimation of $\mathrm{P}$, an instance was carried out in Morocco by Reda et al. [32] which assessed the performance of empirical regression models combined with variable selection algorithms to predict total $\mathrm{P}$ and Olsen $\mathrm{P}$, under variable soil texture conditions. The study showed that Olsen P prediction with Support Vector Machine regression coupled with Genetic Algorithm exhibited the best performance and resulted in a wide variation in regression accuracy between the different combinations of algorithms and soil textures.

Potassium: Few studies have estimated K content using remote sensing data. Among these studies, was Abdel-Rahman et al. [33] who used ground-based hyperspectral data to build prediction models for the concentration of Swiss chard foliar macronutrients under four partial least square regression (PLSR) approaches using rainwater, tap water, and wastewater. The validation of the predictive models was assessed through $R^{2}$ after leave one out cross validation $\left(\mathrm{R}^{2}\right.$-LOOCV) and root mean square error (RMSE) metrics. The authors [33] have found that the different approaches exhibited better predictive accuracy of the Swiss chard foliar of K content, mostly the ones developed under tap water fertigation treatment. Another recent study [20] coupled soil chemical analyses with moderate-resolution (i.e., Landsat-8 imagery) and high-resolution remote sensing (VNIR-SWIR spectroscopy) datasets for the prediction of the content of $\mathrm{K}$ among other soil nutrients in arid zone in Egypt. The spatial prediction of soil $\mathrm{K}$ quantities using partial least- squares regression (PLSR) from ground hyperspectral data and Landsat images, achieved a high validation accuracy (i.e., $\mathrm{R} 2$ of 0.91 and 0.55 , respectively).

With the recent advances made in the hyperspectral field, it is becoming more widely available to use these data in agricultural applications, particularly with the launch of regional airborne hyperspectral missions (e.g., AVIRIS NG) and the development from low-cost handheld solutions to global spaceborne hyperspectral sensors (e.g., Hyperion EO1, PRISMA, EnMAP). Nevertheless, it can be a promising technology as it will feature higher capabilities for acquiring a detailed spectral response of NPK content, as opposed to multispectral imaging, hyperspectral images have not been widely used over Africa, most probably due to several limitations (i.e., few operational airborne and spaceborne missions, and dimensionality of the high-volume datasets storage requirements). A recent study by Khechba et al. [34] has reported that the African scientific community can typically encounter such limitations [33]. To our knowledge, no research in Africa had previously assessed hyperspectral remote sensing-based models that fall within optimization of NPK rates in arid and semi-arid region in Africa on any kind of crops.

Although there is much potential in these hyperspectral platforms, significant development is required by African scientists to develop ways for translating the large amount of data collected into quantities that can be used for precision agriculture. In this study, we aim to (i) conduct a review to assess the status of NPK quantification and assessment over the African continent using remote sensing during the last decade, and (ii) to identify knowledge gaps in this field of quantification of soil and crop NPK content using remote sensing data in Africa. To do so, publications that explored the applications in monitoring soil NPK macronutrients in Africa over the timespan 2008-2020 are reviewed in this study. The imaging platforms and sensors, besides the different methods of processing encountered across the literature, will be introduced. Furthermore, performance of spectroscopy, coupled with different algorithms of regression and classification for the quantification of macronutrients, in addition to the covariates affecting the nutrients dynamics in soil were also examined. Furthermore, the pending questions regarding the state of art of the assessment of soil NPK availability through hyperspectral remote sensing will be exhibited. 


\section{Overview of Remote Sensing Sensors Used for NPK Assessment and Mapping}

\subsection{Satellite Mounted Sensors}

Several studies of soil and crop nutrient concentrations used multispectral satellite remote sensing data, as they provide a continuously updated catalog of tiles that map the whole land surface with a decent spatial, spectral resolution, merely at no cost (i.e., Landsat, Sentinel) [35]. These satellite missions allowed the development of time series analysis workflows for the purposes of developing good practices of the integration of variable rate management for large field scale [36]. The high temporal resolution of these constellations have made possible the consideration of soil and crops temporal variability within the growing season over a large timespan [37]. Although similar studies also highlighted the potential of remote sensing data to provide quantitative insights about soil and crop nutrients status [38], they emphasized that the resulting accuracy level amounts essentially to the spatial and spectral resolution of the input images [20]. Others pointed out to the constraint of the limited number of spectral bands in multispectral data, which hinders the soil and crop spectral analyses. They rather suggested for better results, the employment of hyperspectral data [39]. Despites the few missions that have been launched so far, they covered most of the land surface during a large period of time (e.g., Hyperion EO-1). In this context, a recent hyperspectral Satellite mission "PRISMA" launched in 2019 [40], collects data within the 350-2500 nm wavelength range with a spectral resolution of $10 \mathrm{~nm}$ all around the globe. It holds many opportunities for a better monitoring of ground targets, especially the investigation of crops and soils variability [41].

Several studies that have been conducted over the world to monitor performances of hyperspectral imagery and multispectral imagery in precision agriculture applications, notably for estimating Nutrient content in soil and crops. For instance, in a recent study, [8] used the Derivative Analysis for Spectral Unmixing (DASU) approach on hyperspectral signatures of different types of soils and found that endmember features of NPK compost and soil have diagnostic spectral absorption bands respectively. Another study [20] compared Visible and NIR spectroscopy with Landsat 8 multispectral imagery to investigate the spatial variability soil nutrients under arid climate. The authors reported better performances of using hyperspectral imagery than using Landsat imagery for both research purposes. Similarly, Bostan et al. [42] compared Hyperion and Landsat images for crop classification and found that higher classification accuracy can be achieved by using hyperspectral imagery. [43]. Nevertheless, reaching a high spatial resolution from satellite perspective has always been a challenge (e.g., $30 \mathrm{~m}$ for PRISMA, and EnMAP) with respect to the level of accuracy required for estimating nutrients, crop yield and health assessment, and yet remains not high enough for deployment in precision agriculture and variable rate management practices.

\subsection{Airborne and Unmanned Aerial Vehicles (UAVs) Mounted Sensors}

Airborne and Unmanned Aerial Vehicles (UAV) multi-sensor imaging is being globally used in capturing remote sensing data for various soil and crops properties, including NPK. Its operating affordability, low cost and high use flexibility made its integration in precision agriculture operations much more practical, especially for soil and crop nutrient management purposes [44]. In fact, the release of UAV compatible digital RGB, multispectral, thermal and hyperspectral sensors, enabled in-depth remote sensing investigations of precision agriculture questions, mainly those related to crop yield estimation and field nutrients variability assessment, as these mounted sensors permit having control over a wide range of setups, ranging over the acquisition operation, the mission schedule, flight altitude, and the geographical coverage, which help achieving a high spatial resolution [43]. Other advantages of these platforms are that they allow users to drastically reduce the atmospheric effect on resulting imagery, as well as turning away the cloud drawbacks that often face optical satellites and high-altitude airborne mounted optical sensors [45]. The spectral resolution of sensors on-board UAV can vary from being multispectral, with few specific wide bands, to hyperspectral with continuous narrow hundreds of bands; 
both covering a range between $400-2500 \mathrm{~nm}$ [46]. In terms of the application on precision fertilization, previous studies highlighted that UAV hyperspectral sensors can lead to highly accurate estimates of crop nutrients, especially leaf $\mathrm{N}$ [44].

To balance the tradeoff between the accuracy and the cost of the nutrient estimations in a crop field, various experimental trials exist, from the sole rely on multispectral [47]or hyperspectral data captured in a single campaign [45], all the way to the combination of ground-measured data of soil and/or crop nutrients concentrations with a time series of UAV's flight missions' data, captured at different crop growth [48]. Insights about soil and crop nutrient contents are brought through the analysis of the UAV surface reflectance responses from designed crop plots, using ground-measured data, and the formulation of appropriate spectral indices. These explain most of the statistical variations in nutrients content by the combination of the bands of interest whether (i) inside an interpretable parametric model [44]; (ii) the incorporation of the entire spectrum response into the inverse algorithms of a canopy RTM [15]; (iii) or by means of machine and deep learning algorithms. It is worth mentioning that the wide use of machine learning algorithms and their growing ubiquity in the data science field, have exhibited a potential track for remote sensing based variable rate fertilization, to find significant patterns about nutrient availability in the crop field [49].

\subsection{Ground-Based and Proximal Sensing}

Although ground-based hyperspectral reflectance data can be quickly measured using a spectroradiometer (e.g., ASD FieldSpec, [44,50,51]) and have been widely used for observing canopy and leaf-level spectral features [52-54]. Spectroscopy ground-based measurements are limited to a few numbers of field sites, and they cannot be applied across large areas; in contrast to airborne and space borne hyperspectral imaging sensors. There exist other advanced sensing technologies based on physical properties to characterize soil properties. As soil conductivity is enabling the characterization of soil physical properties (i.e., texture, water content, salinity), vis-NIR diffuse reflectance spectroscopy [55] and Gamma- ray spectroscopy [56] serve in retrieving properties with direct spectral responses (e.g., OC, TN, SOM, MC, and clay) under laboratory conditions, which provide accurate results as compared to aerial measurement, due to the entire elimination of the atmospheric errors usually affecting the measurements. It is worth noting that properties soil chemical properties (e.g., $\mathrm{P}$ and $\mathrm{K}$ ) don't have direct spectral responses, let alone $\mathrm{K}$ variation in soil is hard to identify with NIR spectroscopy. Most of these instrument exhibit high deployment charges, hence future research should focus on finding the optimal tradeoff between the profitability of adopting advanced sensing methods, the spatial extent beside the accuracy they provide versus the soil conventional laboratory analysis [57].

\section{Synthesis of Reviewed and Retained Publications}

This synthesis review focus on presenting a categorization scheme for distinct investigated NPK, followed by a discussion of the important findings with regards to remote sensing data sources, modeling and spatial prediction approaches. Several papers that show how remote sensing data methods can be used to quantify and monitor macronutrient concentrations in soil and crops were introduced and discussed. "Nitrogen", "Phosphorus", "Potassium" "remote sensing", "Soil" and "Crop" were the main keywords which we based our document search on literature databases. To this end, we have employed the same query exercise with different literature databases (i.e., Scopus, Google Scholar, and Web of Science), and have chosen the most performant one, which is the Web of Science database. It is important to mention that the query was applied to the entire paper sections, including the title, abstract, and the keywords. Furthermore, this study searched for publications that based their investigations on remote sensing data to delineate key absorption features of NPK in soil and/or crops features and benchmarked the performance of different regression and machine learning methods in achieving spatial prediction. Our study aimed to cover the time frame ranging from 2008 all the way to 2021, as 2008 marked the year 
when widely used remote sensing imagery (i.e., Landsat) became free open access for scientists. However, it's important to mention that no publication was found for 2008 and 2009. The African continent was used as the key search. Our first query results showed a 6077 publications, and the second query that integrated remote sensing keywords led to 47 articles, and a scoping exercise we retained 26 publications designed to answer the study objectives. Figure 1 summarize the entire research and filtering process we carry out in Web of Science database.

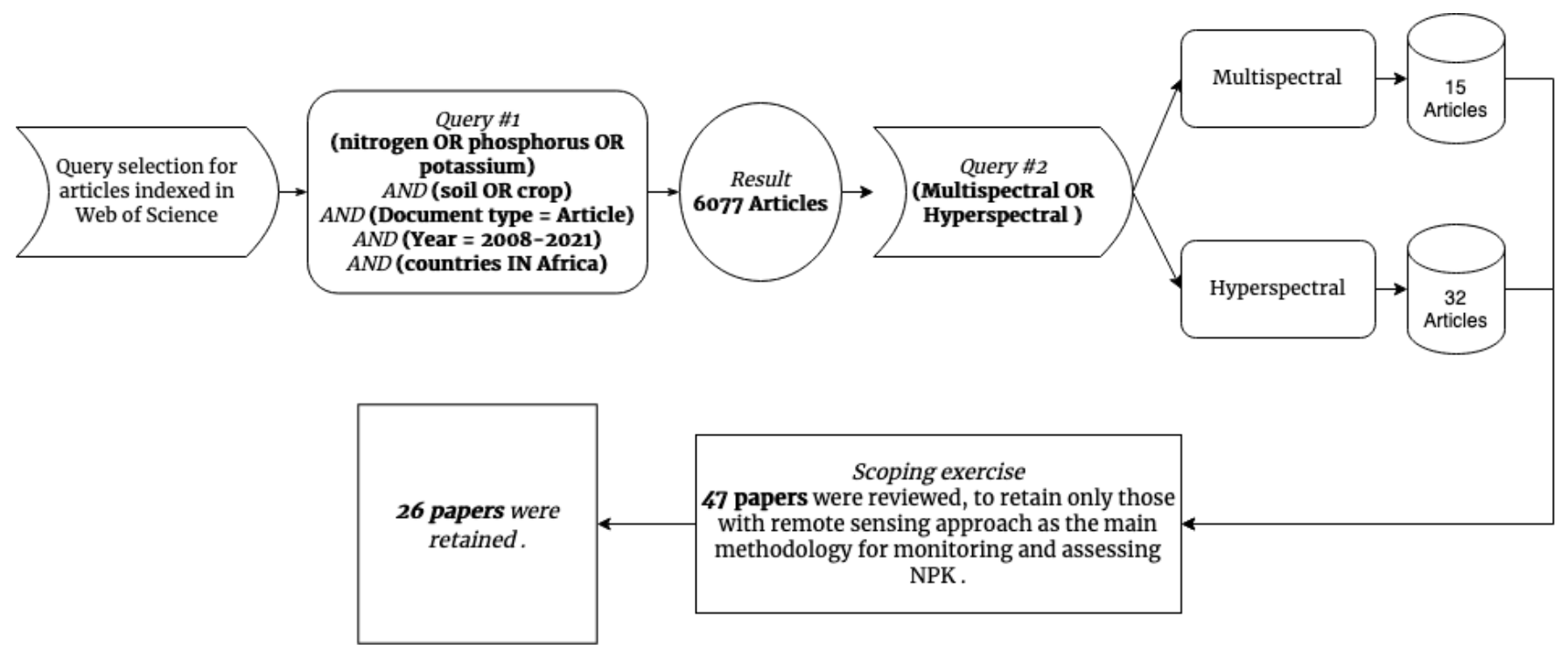

Figure 1. Flowchart of the methodology used for the literature review queries.

In addition, to the time period and geographical region, our search was based on the following set of search criteria: (i) the papers must be published in indexed journals and (ii) they had to directly address soil or crop NPK quantification using remote sensing data. In terms of the geographical footprint, the resulting studies were conducted in eleven African countries: Algeria, Burkina Faso, Egypt, Kenya, Madagascar, Malawi, Morocco, Nigeria, South Africa, Tanzania, and Zimbabwe (Figure 2). The ultimate result is a logic diagram summarizing the selected papers that studied individual N, P, K, or a combination of more than one nutrient. 


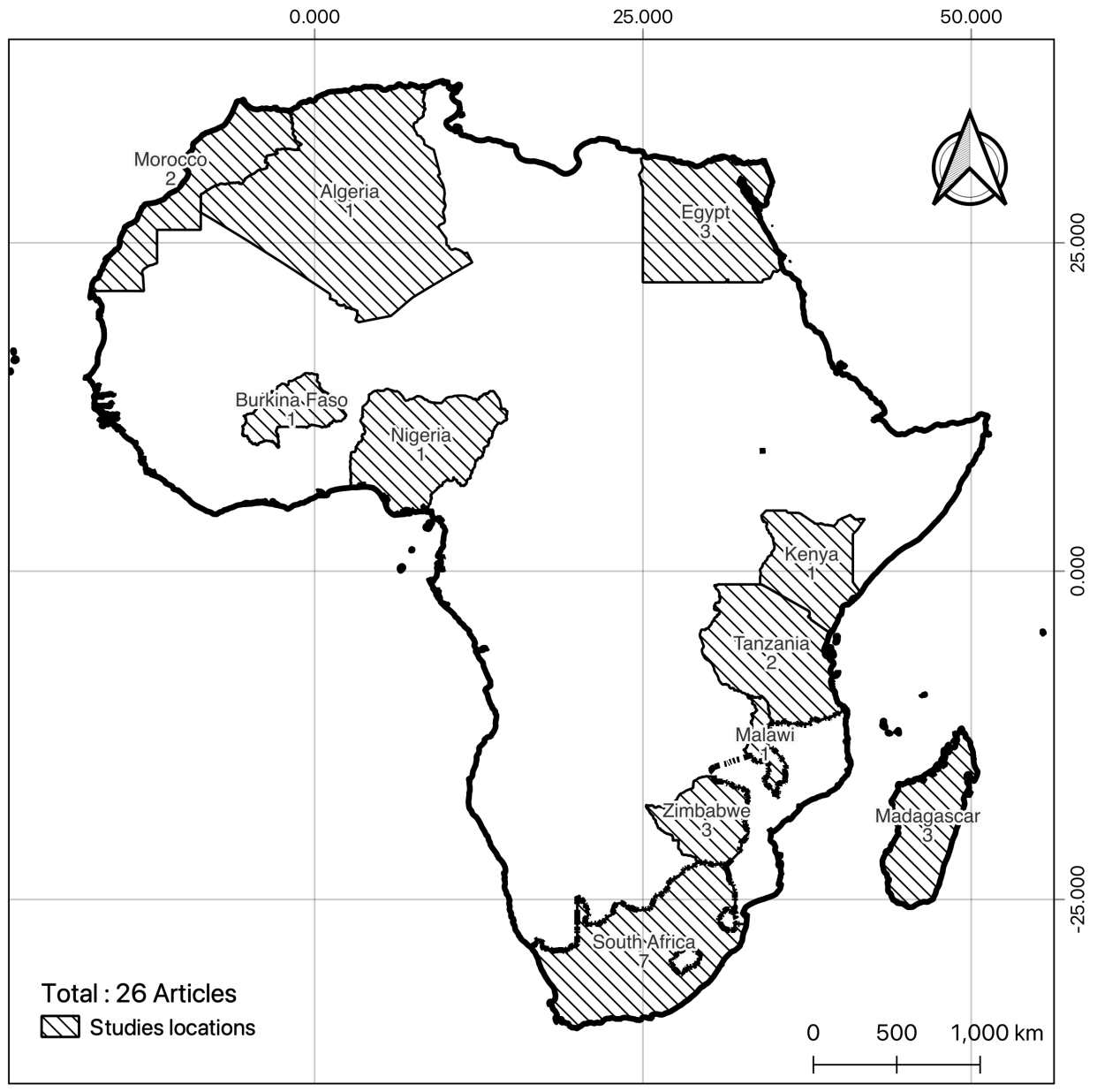

Figure 2. Map showing the the African countries investigated (hatched) in this study.

\section{Results and Discussion}

The results of our research showed that between 2008 and 2021, only 26 publications that explicitly aimed to quantify soil and crops NPK content using remote sensing in Africa were retained (Table 1). In term of the studied nutrients covered in the 26 retained studies, $\mathrm{N}$ has ranked first with 23 publications in total, followed by $\mathrm{P}$ with 12 papers, and $\mathrm{K}$ with 6 papers (Figure 3). It is important to mention that the proportion of these remote sensing-based studies compared to those that used the traditional ground-based monitoring methods (i.e., other than remote sensing techniques) to monitor NPK in Africa remain very low (i.e., about 846 papers, figure not shown here).

This reviewing study indicates that recent studies in Africa are increasingly adopting remote sensing based spatial prediction approach in comparison to other tools for monitoring the variation of soil and crops NPK content. This is consistent with a recent study [34] that reported the same increasing trend regarding the use of remote sensing for field studies in Africa. The presented case studies showcased a difference in costeffectiveness and performance between remote sensing approach and traditional soil and crop sampling methods. It is worth mentioning that a minimum field sampling is still required for remote sensing-based studies, as a step to validate the prediction models with ground truth measurements. 
Table 1. Summary of previous studies that quantified NPK in vegetations and soil.

\begin{tabular}{cccccc}
\hline Country & $\begin{array}{c}\text { Publication } \\
\text { Year }\end{array}$ & $\begin{array}{c}\text { Targeted } \\
\text { Nutrient }\end{array}$ & Soil/Crop & $\begin{array}{c}\text { Remote Sensing } \\
\text { Source }\end{array}$ & Reference \\
\hline South Africa & 2010 & N & Sugarcane & HSS & {$[58]$} \\
South Africa & 2010 & N & Sugarcane & HSS & {$[50]$} \\
South Africa & 2011 & N & Maize & HSS & {$[59]$} \\
South Africa & 2012 & NP & Forage & HSS & {$[60]$} \\
South Africa & 2013 & NP & Grass & HSS & {$[61]$} \\
Kenya & 2016 & N & Mixte* & MS-L8 & {$[62]$} \\
Zimbabwe & 2016 & NP & Maize & UAV & {$[63]$} \\
Burkina Faso & 2017 & N & Soil & MS-L8, RE & {$[19]$} \\
Egypt & 2017 & N & Peanut & HSS & {$[64]$} \\
Madagascar & 2017 & N & Soil & HSS & {$[65]$} \\
South Africa & 2017 & NPK & Swiss chard & HSS & {$[33]$} \\
Tanzania & 2017 & N & Coffee & MS-S2 & {$[66]$} \\
Zimbabwe & 2017 & N & Maize & UAV & {$[67]$} \\
Zimbabwe & 2017 & P & Wheat & US-L8 & {$[68]$} \\
Tanzania & 2018 & NP & Rice & HSS & {$[69]$} \\
Madagascar & 2019 & P & Maize & HSS & {$[71]$} \\
South Africa & 2019 & $\mathrm{P}$ & Eucalyptus & HSS & {$[72]$} \\
Algeria & 2019 & N & Wheat & MS-L8, HSS & {$[20]$} \\
Egypt & 2020 & NPK & Soil & HSS & {$[73]$} \\
Egypt & 2020 & N & Maize & HSS & {$[74]$} \\
Africa & 2021 & NPK & Soil & UAV & {$[25]$} \\
Madagascar & 2021 & NPK & Soil & UAV & {$[75]$} \\
Malawi & 2021 & N & Maize & MS-L8 & {$[48]$} \\
Morocco & 2021 & N & Wheat & HSI & {$[76]$} \\
Morocco & 2021 & NPK & Soil & MS-S2, MS-L8 & {$[77]$} \\
Nigeria & 2021 & NPK & Soil & \\
\hline
\end{tabular}

${ }^{*}$ Maize, Beans, Wheat, Potatoes. N :Nitrogen; P: Phosphorus; K: Potassium; HSS: Hyperspectral spectroscopy; HSI: Hyperspectral imaging; MS-L8: Multispectral Landsat 8; UAV MS: Unmanned Arial Vehicle Multispectral; RE: RapidEye; MS S2: Multispectral Sentinel 2.

Figure 3 shows the distribution of papers that used multispectral versus hyperspectral remote sensing data since 2008. Overall, the number of publications that employed hyperspectral-based remote sensing data for NPK monitoring has significantly increased over time compared to studies that used multispectral remote sensing. This is consistent with previous studies that have demonstrated the superior performance of hyperspectral imagery over multispectral images in monitoring soil properties including soil and crop NPK content $[39,78]$. 


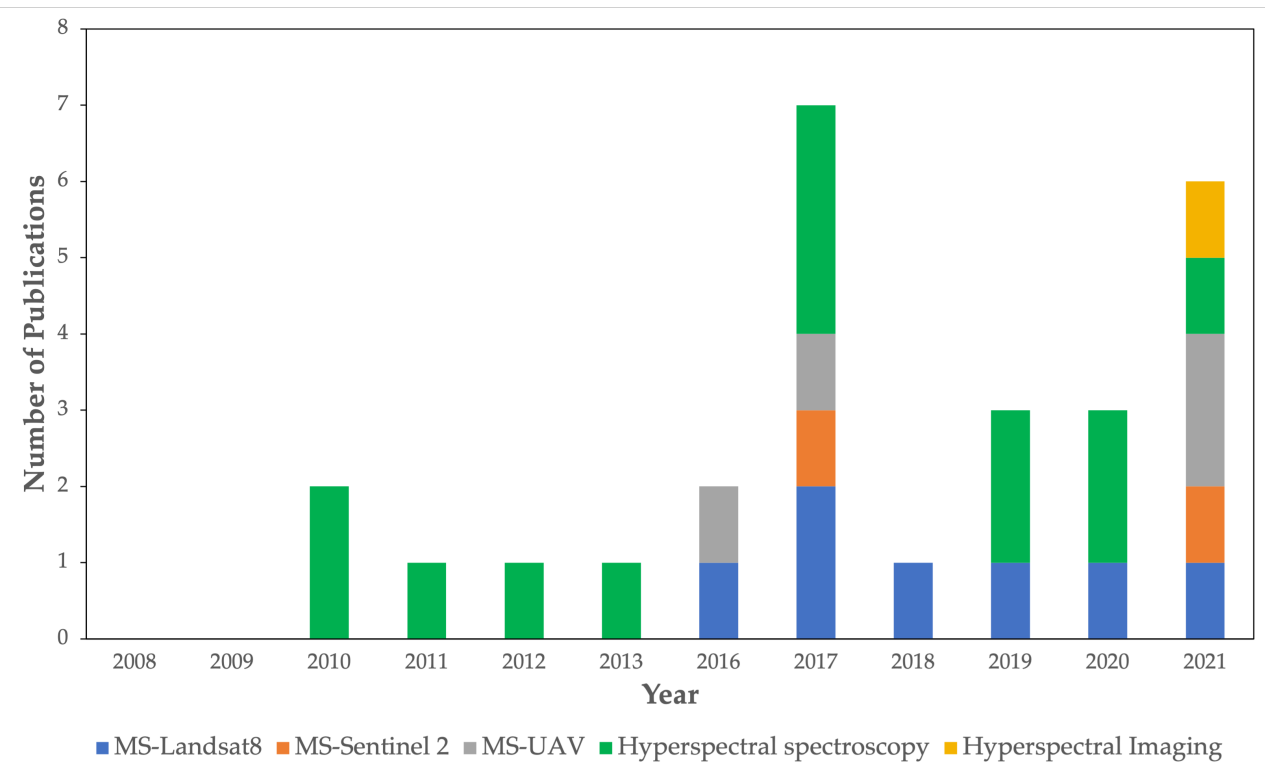

Figure 3. Proportion of the 26 selected studies that used multispectral vs hyperspectral data to monitor NPK over Africa between 2008 and 2021).

Our results also showed that more than half of the selected papers (i.e., nine publications) used hyperspectral spectroscopy approaches for NPK monitoring and assessment; most likely because the high spectral resolution of hyperspectral data can be used to select particular spectral regions, bands, or features that are most sensitive to describe NPK content both in crop the spectral bands/regions that allowed to characterize NPK (Figure 4). Overall, the number of the found specific bands for $\mathrm{N}$ and $\mathrm{P}$ are significantly higher than the bands for K (Figure 4). Despite its outstanding performance, hyperspectral imaging has been utilized comparatively less in African operational agricultural applications in the past few decades. This might be explained by the high cost of imagery and various other technical and practical challenges (e.g., access to the specialized software needed and the skills to process this the large data volume) [34]. This might also explain why most of the papers reviewed in this study used spectroscopy instead of hyperspectral imaging. However, we believe that more studies will be conducted in the near future using hyperspectral imagery (i.e., PRISMA [76]) to monitor NPK over Africa, as these images are becoming freely open accessed for African scientists.

Recently, precision agriculture has emerged as a promising technique [79] and aims to optimize farm inputs (i.e., NPK, SOC) by focusing on the right management practices, at the right time, in the right place [80]. This concept is based on monitoring and responding to intra-field variability in plants and soil. Thus, UAV-based remote sensing approach can provide an effective way to analyze the heterogeneity of agricultural surfaces at the field-scale [81]. This fast emerging technology provides the opportunity to reveal new insights into agricultural processes and represents a game-changing sensing platform for precision agriculture over the world, including Africa. The key advantages of UAV-based remote sensing are their capacities to collect data on demand and at very high resolution. Our investigation has confirmed the increasing trend in the use of UAV technologies. Indeed, we have found that since 2016 on-board UAV sensors have been increasingly used to assess and monitor NPK both in soil and crop, especially because of their unprecedented spatiotemporal resolutions. Thus, it is expected that in the coming decade, African scientists will benefit from the advancements in drone multi-sensor derived data (e.g., hyperspectral, multispectral, thermal), and thereby produce a high number of publications on NPK assessment to ensure sustainable production and development. 

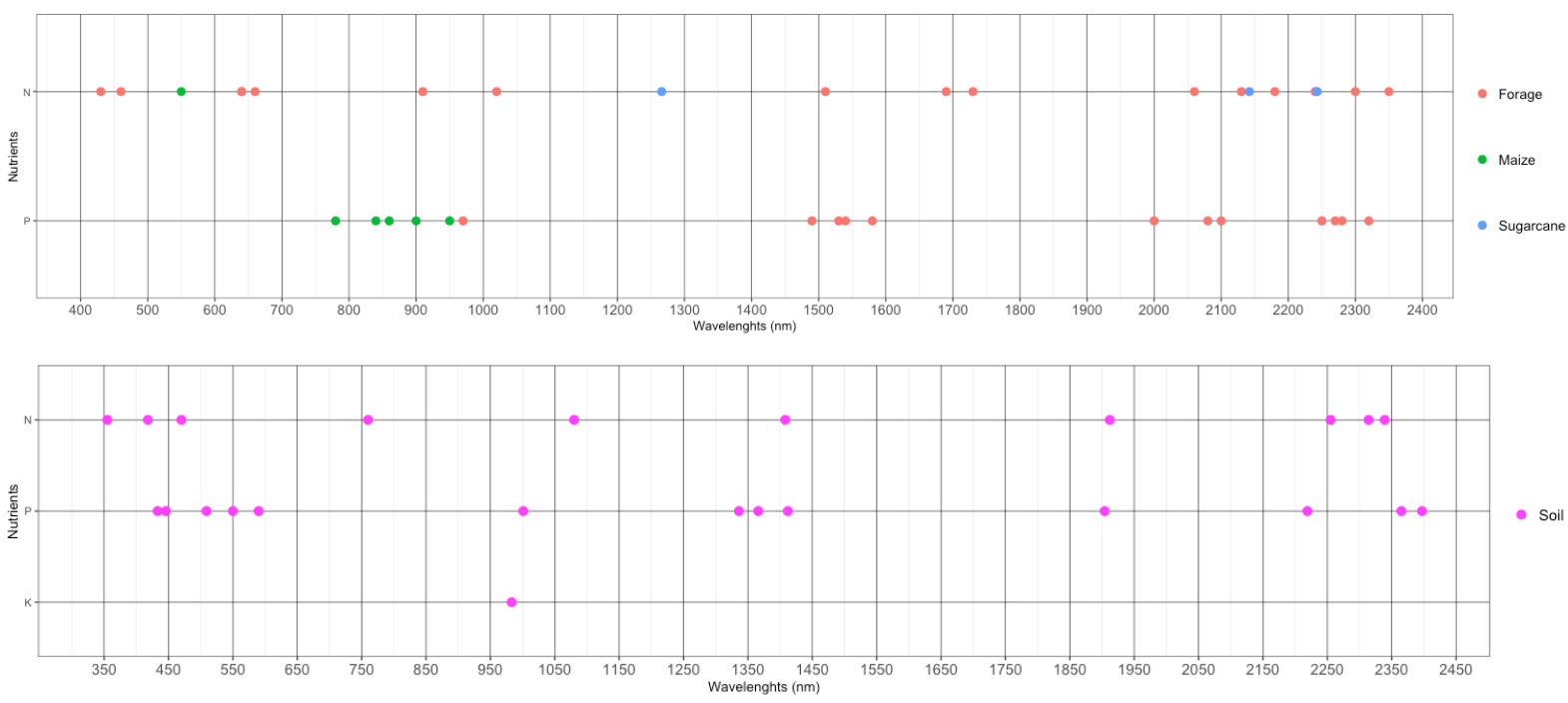

Figure 4. Graphs showing some of the selected 26 papers that used spectral regions, bands, and/or features that are most sensitive to describe NPK content both in crops and soil (top and bottom graphs, respectively)

Finally, our investigation has focused on reviewing the current state of research regarding monitoring soil and crop NPK content in Africa using remote sensing (Table 2); which has an important interest towards promoting the appropriate use fertilization practices. In addition to the remote sensing techniques to assess NPK, we should mention that digital soil maps can be important products for NPK soil management and monitoring for precision agriculture applications in Africa [82]. However, the accuracy and the extent of such maps in Africa remains questionable. To date, the first spatial predictive map of soil nutrients, including NPK, was conducted in sub-Saharan Africa at $250 \mathrm{~m}$ resolution [83] and narrowed down recently to $30 \mathrm{~m}$ [74]. Despite the reported good precision of certain soil attributes (i.e., $P$ ) of these recent maps, their accuracy and uncertainty need further investigation. 
Table 2. Key findings, The most frequently used remote sensing and regression methods as defined by the selected publications.

\begin{tabular}{|c|c|c|c|}
\hline Findings & Remote Sensing Source & Modeling Approach & Reference \\
\hline $\begin{array}{l}\text { First-order derivatives of sugarcane leaf } \\
\text { reflectance in VIS_NIR demonstrated high } \\
\text { correlation with the underlying N concentration. }\end{array}$ & Spectroscopy & Simple linear regression & [58] \\
\hline $\begin{array}{l}\text { Red-edge Index based on leaf reflectance } \\
\text { exhibited a linear relation to N concentration. }\end{array}$ & Spectroscopy & Spectral vegetation indices & {$[50]$} \\
\hline $\begin{array}{l}\text { Chlorophyll absorption centre wavebands-based } \\
\text { indices were the best performers in estimating } \\
\mathrm{N} \text { concentration. }\end{array}$ & Spectroscopy & $\begin{array}{l}\text { Spectral vegetation indices } \\
\text { Linear regression and bootstrapping }\end{array}$ & [59] \\
\hline $\begin{array}{l}\text { Red-Edge Position showed a significant } \\
\text { association to forage nitrogen content, } \\
\text { whereas the variation in foliar phosphorus } \\
\text { concentrations seemed to be associated with } \\
\text { sugars and starch absorption features. }\end{array}$ & Spectroscopy & Linear regression & {$[60]$} \\
\hline $\begin{array}{l}\text { Grass Protein absorption features contributes } \\
\text { significantly to the prediction of foliar } \mathrm{N} \text { content. } \\
\text { However no spectral features were found to } \\
\text { be explaining the foliar P concentration. }\end{array}$ & Spectroscopy & Non-linear PLSR & {$[61]$} \\
\hline $\begin{array}{l}\text { The topographical and climatic parameters showed } \\
\text { significant influence on the spatial variation of } \\
\text { the estimated total nitrogen stock in soil }\end{array}$ & Landsat & Bivariate Correlations & [62] \\
\hline $\begin{array}{l}\text { High correlation between Leaf Chlorophyll content } \\
\text { and the associated } \mathrm{N} \text { concentration across under } \\
\text { different } \mathrm{N} \text { fertilization rates. }\end{array}$ & Multispectral UAV & $\begin{array}{l}\text { Multiple linear regression } \\
\text { Multiple Linear Regression-Kriging } \\
\text { Geographically Weighted Re-gression } \\
\text { Geographically Weighted Regression-Kriging }\end{array}$ & {$[63]$} \\
\hline $\begin{array}{l}\text { The weak association observed between soil } \mathrm{N} \text { and } \\
\text { soil reflectance data is due to the heterogenity in the } \\
\text { agricultural soil management practices, and the } \\
\text { variability of the climatic factors. }\end{array}$ & Landsat-RapidEye & PLSR & [19] \\
\hline
\end{tabular}


Table 2. Cont.

\begin{tabular}{|c|c|c|c|}
\hline Findings & Remote Sensing Source & Modeling Approach & Reference \\
\hline $\begin{array}{l}\text { Studied spectral indices showed a significant } \\
\text { relationship with nitrogen concentration and } \\
\text { peanut nitrogen uptake. }\end{array}$ & Spectroscopy & Random Forest & {$[64]$} \\
\hline $\begin{array}{l}\text { Iterative stepwise elimination-based PLS performed } \\
\text { a high prediction of soil total nitrogen from the } \\
\text { first derivative of the Visible and Near-Infrared } \\
\text { diffuse reflectance spectra. }\end{array}$ & Spectroscopy & regression analys & [65] \\
\hline $\begin{array}{l}\text { Inspite of the good performance of the model in } \\
\text { predicting foliar NPK content from hyperspectral } \\
\text { data, no specific region in the VIS-NIR spectra } \\
\text { has made a particular absorption feature for } \\
\text { foliar NPK concentration. }\end{array}$ & Spectroscopy & PLSR & [33] \\
\hline $\begin{array}{l}\text { Combining optimized bands of Sentinel } 2 \text { and } \\
\text { derived vegetation indices achieved optimal } \\
\text { models for the estimation of coffee foliar } \mathrm{N}\end{array}$ & Sentinel 2 & $\begin{array}{l}\text { MLR, RF, SVM } \\
\text { Stochastic Gradient Boosting (SGB) }\end{array}$ & {$[66]$} \\
\hline $\begin{array}{l}\text { Some visible bands showed a significant but } \\
\text { weak correlation with } \mathrm{P} \text { content in maize } \\
\text { leave, In contrast to the multispectral bands } \\
\text { that significantly correlated with the difference } \\
\text { in grain yield and } \mathrm{N} \text { content under different } \mathrm{P} \\
\text { fertilization methods. }\end{array}$ & UAV & Multi Linear Regression & [67] \\
\hline $\begin{array}{l}\text { The relative greener area index showed a } \\
\text { significant association with } \mathrm{N} \text { status in wheat } \\
\text { crop under different } \mathrm{N} \text { fertilizers treatments. }\end{array}$ & Multispectral UAV & PLSR & [70] \\
\hline $\begin{array}{l}\text { Wavenbands that are sensitive to } \mathrm{Al} \text { and } \mathrm{Fe} \text { are found } \\
\text { to be informative for estimating bound Extractable } \\
\mathrm{P} \text { bound contents. }\end{array}$ & Multispectral UAV & PLSR & {$[71]$} \\
\hline
\end{tabular}


Table 2. Cont.

\begin{tabular}{|c|c|c|c|}
\hline Findings & Remote Sensing Source & Modeling Approach & Reference \\
\hline $\begin{array}{l}\text { The Model population Analysis framework } \\
\text { associated with PLSR algorithm accurately } \\
\text { selected optimal spectral absorption signals } \\
\text { in the SWIR region that precdicts of leaf } \\
\text { nitrogen content. }\end{array}$ & Landsat-Spectroscopy & $\begin{array}{l}\text { Simple linear regression (SLR) } \\
\text { Multivariate Regression Analyses }\end{array}$ & [20] \\
\hline $\begin{array}{l}\text { Reflectance resulting from spectroscopy } \\
\text { demonstrated better estimation of soil NPK than } \\
\text { satellite band reflectance }\end{array}$ & Spectroscopy & Multi Linear Regression & [73] \\
\hline $\begin{array}{l}\text { Penalized linear discriminant analysis (PLDA) } \\
\text { applied on crop reflectance response was able } \\
\text { to distinguish between different gradients of } \\
\text { moisture and nitrogen induced stress. }\end{array}$ & Spectroscopy & PLSR, RF & [25] \\
\hline $\begin{array}{l}\text { The 1D-Convolutional Neural Network model } \\
\text { showed a significant improvement in predicting } \\
\text { soil P and the associated spectral wavebands. }\end{array}$ & Multispectral UAV & & [75] \\
\hline $\begin{array}{l}\text { RTVI index highly correlated with } \mathrm{N} \text { uptake } \\
\text { for all tested wheat varieties. }\end{array}$ & Multispectral UAV & Random Forest & [48] \\
\hline $\begin{array}{l}\text { The topographic attributes, Land surface } \\
\text { temperature, soil bulk density, water holding } \\
\text { capacity and soil organic matter significantly } \\
\text { contributed to the variation of soil NPK. }\end{array}$ & Landsat & & {$[77]$} \\
\hline
\end{tabular}




\section{Conclusions}

This study was conducted to determine the state of art of multispectral and hyperspectral remote sensing capabilities in quantifying the variations of soil and crop NPK content over selected African countries. The low cost and spatial extent of this approach has uncovered the potential of RS in monitoring soil macronutrients with the aim of optimizing input through the adoption of variable rate fertilization and ultimately narrow the yield gap. The novelty of this study not only lies in the exhibition of the studies carried out in macronutrient assessment with a focus on the African continent, but more importantly, showed the relationship between the reflectance of different soils properties and crops and the underlying variation of NPK. Further analysis and assessment at the continental scale, are required to reach a level of a maturity in deploying remote sensing for the application of variable rate fertigation. The most used and recent RS mapping methods including support vector machine (SVM) method, random forest (RF) regression models, principal component analysis (PCA), partial least square regression (PLSR) analysis, multiple regression analysis, neural network model and various spectral soil and vegetation indices derived mostly from red-edge and NIR were summarized. Finally, we aim for this review to highlights not only the knowledge gap and the pending questions in the field, but also identify the most sensitive wavelengths to the variation of NPK in soil and crops.

Author Contributions: All the authors (K.M.; A.L.; K.K., D.D. and A.C.) have contributed substantially to this manuscript. Conceptualization, A.L., D.D. \& A.C.; methodology, K.M., A.L., D.D., K.K. \& A.C.; validation, K.M., A.L., D.D., K.K. and A.C.; formal analysis, K.M., K.K. and A.L.; investigation, K.M. and A.L.; writing-original draft preparation, K.M.; A.L. and K.K; writing-review and editing, K.M., A.L., D.D., K.K. and A.C.; supervision, A.L. and A.C.; writing review and editing manuscript, K.M.; A.L.; D.D.; K.K. and A.C.; project administration, A.L., D.D. and A.C. funding acquisition, A.C. and A.L. All authors have read and agreed to the published version of the manuscript.

Funding: This project has been financially supported by the OCP group foundation and the Mohammed VI Polytechnic University (UM6P). The lead author received financial support from the UM6P.

Data Availability Statement: Data sharing is not applicable to this article.

Acknowledgments: The authors acknowledge all the technical support of those who helped in conducting the study. The manuscript has been checked for spelling and grammar by the UM6P English language specialist team. We also thank the academic editor and anonymous reviewers for accepting to review the earlier version of the manuscript.

Conflicts of Interest: The authors declare no conflict of interest.

\section{References}

1. Tripathi, A.D.; Mishra, R.; Maurya, K.K.; Singh, R.B.; Wilson, D.W. Estimates for World Population and Global Food Availability for Global Health. Role Funct. Food Secur. Glob. Health 2019, 3-24. [CrossRef]

2. FAO. The Future of Food and Agriculture. Food Agric. Organ. United Nations 2017, 20, 1-52.

3. Saito, K.; Vandamme, E.; Johnson, J.M.; Tanaka, A.; Senthilkumar, K.; Dieng, I.; Akakpo, C.; Gbaguidi, F.; Segda, Z.; Bassoro, I.; et al. Yield-limiting macronutrients for rice in sub-Saharan Africa. Geoderma 2019, 338, 546-554. [CrossRef]

4. Lu, H.J.; Ye, Z.Q.; Zhang, X.L.; Lin, X.Y.; Ni, W.Z. Growth and yield responses of crops and macronutrient balance influenced by commercial organic manure used as a partial substitute for chemical fertilizers in an intensive vegetable cropping system. Phys. Chem. Earth 2011, 36, 387-394. [CrossRef]

5. Sharpley, A.N.; Menzel, R.G. The impact of soil and fertilizer phosphorus on the environment. Adv. Agron. 1987, 41, 297-324. [CrossRef]

6. Späti, K.; Huber, R.; Finger, R. Benefits of Increasing Information Accuracy in Variable Rate Technologies. Ecol. Econ. 2021, 185, 107047. [CrossRef]

7. Saïdou, A.; Janssen, B.H.; Temminghoff, E.J. Effects of soil properties, mulch and NPK fertilizer on maize yields and nutrient budgets on ferralitic soils in southern Benin. In Agriculture, Ecosystems and Environment; Elsevier: Amsterdam, The Netherlands, 2003; Volume 100, pp. 265-273. [CrossRef]

8. Patel, A.K.; Ghosh, J.K.; Sayyad, S.U. Fractional abundances study of macronutrients in soil using hyperspectral remote sensing. Geocarto Int. 2020, 1-20. [CrossRef]

9. Blondlot, A.; Gate, P.; Poilvé, H.; Others. Providing operational nitrogen recommendations to farmers using satellite imagery. Precis. Agric. 2005, 5, 345 . 
10. Gao, P.; Zuo, Z.; Zhang, R.; Qiu, Y.; He, R.; Gao, R.; Gui, R. Optimum nitrogen fertilization for phyllostachys edulis productivity and photosynthetic response. Agron. J. 2016, 108, 448-458. [CrossRef]

11. Quemada, M.; Gabriel, J.L.; Zarco-Tejada, P. Airborne hyperspectral images and ground-level optical sensors as assessment tools for maize nitrogen fertilization. Remote Sens. 2014, 6, 2940-2962. [CrossRef]

12. Jacquemoud, S.; Verhoef, W.; Baret, F.; Bacour, C.; Zarco-Tejada, P.J.; Asner, G.P.; François, C.; Ustin, S.L. PROSPECT + SAIL models: A review of use for vegetation characterization. Remote Sens. Environ. 2009, 113, S56-S66. [CrossRef]

13. Thorp, K.R.; Wang, G.; West, A.L.; Moran, M.S.; Bronson, K.F.; White, J.W.; Mon, J. Estimating crop biophysical properties from remote sensing data by inverting linked radiative transfer and ecophysiological models. Remote Sens. Environ. 2012, 124, 224-233. [CrossRef]

14. Wang, Z.; Skidmore, A.K.; Darvishzadeh, R.; Heiden, U.; Heurich, M.; Wang, T. Leaf Nitrogen Content Indirectly Estimated by Leaf Traits Derived from the PROSPECT Model. IEEE J. Sel. Top. Appl. Earth Obs. Remote Sens. 2015, 8, 3172-3182. [CrossRef]

15. Li, Z.; Li, Z.; Fairbairn, D.; Li, N.; Xu, B.; Feng, H.; Yang, G. Multi-LUTs method for canopy nitrogen density estimation in winter wheat by field and UAV hyperspectral. Comput. Electron. Agric. 2019, 162, 174-182. [CrossRef]

16. Reeves, J.B.; McCarty, G.W. Quantitative analysis of agricultural soils using near infrared reflectance spectroscopy and a fibre-optic probe. J. Near Infrared Spectrosc. 2001, 9, 25-34. [CrossRef]

17. Viscarra Rossel, R.A.; Walvoort, D.J.; McBratney, A.B.; Janik, L.J.; Skjemstad, J.O. Visible, near infrared, mid infrared or combined diffuse reflectance spectroscopy for simultaneous assessment of various soil properties. Geoderma 2006, 131, 59-75. [CrossRef]

18. Wijewardane, N.K.; Ge, Y.; Wills, S.; Libohova, Z. Predicting Physical and Chemical Properties of US Soils with a Mid-Infrared Reflectance Spectral Library. Soil Sci. Soc. Am. J. 2018, 82, 722-731. [CrossRef]

19. Forkuor, G.; Hounkpatin, O.K.; Welp, G.; Thiel, M. High resolution mapping of soil properties using Remote Sensing variables in south-western Burkina Faso: A comparison of machine learning and multiple linear regression models. PLoS ONE 2017, 12. [CrossRef] [PubMed]

20. Mohamed, E.S.; El Baroudy, A.A.; El-beshbeshy, T.; Emam, M.; Belal, A.A.; Elfadaly, A.; Aldosari, A.A.; Ali, A.M.; Lasaponara, R. Vis-nir spectroscopy and satellite landsat-8 oli data to map soil nutrients in arid conditions: A case study of the northwest coast of egypt. Remote Sens. 2020, 12, 3716. [CrossRef]

21. Pierre, W.H. The Phosphorus Cycle and Soil Fertility 1. Agron. J. 1948, 40, 1-14. [CrossRef]

22. Wollenhaupt, N.C.; Wolkowski, R.P.; Clayton, M.K. Mapping Soil Test Phosphorus and Potassium for Variable-Rate Fertilizer Application. J. Prod. Agric. 1994, 7, 441-448. [CrossRef]

23. Sembiring, H.; Raun, W.R.; Johnson, G.V.; Stone, M.L.; Solie, J.B.; Phillips, S.B. Detection of nitrogen and phosphorus nutrient status in winter wheat using spectral radiance. J. Plant Nutr. 1998, 21, 1207-1233. [CrossRef]

24. Lin, C.; Ma, R.; Zhu, Q.; Li, J. Using hyper-spectral indices to detect soil phosphorus concentration for various land use patterns. Environ. Monit. Assess. 2015, 187, 4130. [CrossRef] [PubMed]

25. Kawamura, K.; Nishigaki, T.; Andriamananjara, A.; Rakotonindrina, H.; Tsujimoto, Y.; Moritsuka, N.; Rabenarivo, M.; Razafimbelo, T. Using a one-dimensional convolutional neural network on visible and near-infrared spectroscopy to improve soil phosphorus prediction in Madagascar. Remote Sens. 2021, 13. [CrossRef]

26. Mahajan, G.R.; Sahoo, R.N.; Pandey, R.N.; Gupta, V.K.; Kumar, D. Using hyperspectral remote sensing techniques to monitor nitrogen, phosphorus, sulphur and potassium in wheat (Triticum aestivum L.). Precis. Agric. 2014, 15, 499-522. [CrossRef]

27. Ansari, M.S.; Young, K.R.; Nicolas, M.E. Determining Wavelenth for Nitrogen and Phosphorus Nutrients Through Hyperspectral Remote Sensing in Wheat (Triticum aestivum L.) Plant. Int. J. -Bio-Resour. Stress Manag. 2016, 7, 653-662.

28. Zhang, Y.; Sui, B.; Shen, H.; Ouyang, L. Mapping stocks of soil total nitrogen using remote sensing data: A comparison of random forest models with different predictors. Comput. Electron. Agric. 2019, 160, 23-30. [CrossRef]

29. Lee, H.; Wang, J.; Leblon, B. Using linear regression, random forests, and support vector machine with unmanned aerial vehicle multispectral images to predict canopy nitrogen weight in corn. Remote Sens. 2020, 12, 2071. [CrossRef]

30. Peng, J.; Manevski, K.; Kørup, K.; Larsen, R.; Andersen, M.N. Random forest regression results in accurate assessment of potato nitrogen status based on multispectral data from different platforms and the critical concentration approach. Field Crop. Res. 2021, 268, 108158. [CrossRef]

31. Dong, Y.; Fu, Z.; Peng, Y.; Zheng, Y.; Yan, H.; Li, X. Precision fertilization method of field crops based on the Wavelet-BP neural network in China. J. Clean. Prod. 2020, 246, 118735. [CrossRef]

32. Reda, R.; Saffaj, T.; Itqiq, S.E.; Bouzida, I.; Saidi, O.; Yaakoubi, K.; Lakssir, B.; El Mernissi, N.; El Hadrami, E.M. Predicting soil phosphorus and studying the effect of texture on the prediction accuracy using machine learning combined with near-infrared spectroscopy. Spectrochim. Acta Part A: Mol. Biomol. Spectrosc. 2020, 242, 118736. [CrossRef]

33. Abdel-Rahman, E.M.; Mutanga, O.; Odindi, J.; Adam, E.; Odindo, A.; Ismail, R. Estimating Swiss chard foliar macro- and micronutrient concentrations under different irrigation water sources using ground-based hyperspectral data and four partial least squares (PLS)-based (PLS1, PLS2, SPLS1 and SPLS2) regression algorithms. Comput. Electron. Agric. 2017, 132, 21-33. [CrossRef]

34. Khechba, K.; Laamrani, A.; Dhiba, D.; Misbah, K.; Chehbouni, A. Monitoring and Analyzing Yield Gap in Africa through Soil Attribute Best Management Using Remote Sensing Approaches: A Review. Remote Sens. 2021, 13, 4602. [CrossRef]

35. Zhu, Z.; Wulder, M.A.; Roy, D.P.; Woodcock, C.E.; Hansen, M.C.; Radeloff, V.C.; Healey, S.P.; Schaaf, C.; Hostert, P.; Strobl, P.; et al. Benefits of the free and open Landsat data policy. Remote Sens. Environ. 2019, 224, 382-385. [CrossRef] 
36. Cilia, C.; Panigada, C.; Rossini, M.; Meroni, M.; Busetto, L.; Amaducci, S.; Boschetti, M.; Picchi, V.; Colombo, R. Nitrogen status assessment for variable rate fertilization in maize through hyperspectral imagery. Remote Sens. 2014, 6, 6549-6565. [CrossRef]

37. Scudiero, E.; Teatini, P.; Manoli, G.; Braga, F.; Skaggs, T.H.; Morari, F. Workflow to establish time-specific zones in precision agriculture by spatiotemporal integration of plant and soil sensing data. Agronomy 2018, 8, 253. [CrossRef]

38. Sishodia, R.P.; Ray, R.L.; Singh, S.K. Applications of remote sensing in precision agriculture: A review. Remote Sens. 2020, $12,3136$. [CrossRef]

39. Candiago, S.; Remondino, F.; De Giglio, M.; Dubbini, M.; Gattelli, M. Evaluating multispectral images and vegetation indices for precision farming applications from UAV images. Remote Sens. 2015, 7, 4026-4047. [CrossRef]

40. Vangi, E.; D'amico, G.; Francini, S.; Giannetti, F.; Lasserre, B.; Marchetti, M.; Chirici, G. The new hyperspectral satellite prisma: Imagery for forest types discrimination. Sensors 2021, 21, 1-19. [CrossRef]

41. Loizzo, R.; Daraio, M.; Guarini, R.; Longo, F.; Lorusso, R.; DIni, L.; Lopinto, E. Prisma Mission Status and Perspective. In Proceedings of the International Geoscience and Remote Sensing Symposium (IGARSS), Kuala Lumpur, Malaysia, 17-22 July 2022; pp. 4503-4506. [CrossRef]

42. Bostan, S.; Ortak, M.A.; Tuna, C.; Akoguz, A.; Sertel, E.; Berk Ustundag, B. Comparison of classification accuracy of co-located hyperspectral and multispectral images for agricultural purposes. In Proceedings of the 2016 Fifth International Conference on Agro-Geoinformatics (Agro-Geoinformatics), Tianjin, China, 18-20 July 2016. [CrossRef]

43. Lu, B.; Dao, P.D.; Liu, J.; He, Y.; Shang, J. Recent advances of hyperspectral imaging technology and applications in agriculture. Remote Sens. 2020, 12, 2659. [CrossRef]

44. Zhu, H.; Liu, H.; Xu, Y.; Guijun, Y. UAV-based hyperspectral analysis and spectral indices constructing for quantitatively monitoring leaf nitrogen content of winter wheat. Appl. Opt. 2018, 57, 7722. [CrossRef]

45. Pölönen, I.; Saari, H.; Kaivosoja, J.; Honkavaara, E.; Pesonen, L. Hyperspectral imaging based biomass and nitrogen content estimations from light-weight UAV. In Remote Sensing for Agriculture, Ecosystems, and Hydrology XV; Neale, C.M.U., Maltese, A., Eds.; SPIE: Bellingham, WA, USA, 2013; Volume 8887, p. 88870J. [CrossRef]

46. Laamrani, A.; Joosse, P.; McNairn, H.; Berg, A.A.; Hagerman, J.; Powell, K.; Berry, M. Assessing soil cover levels during the non-growing season using multitemporal satellite imagery and spectral unmixing techniques. Remote Sens. 2020, $12,1397$. [CrossRef]

47. Osco, L.P.; de Arruda, M.d.S.; Marcato Junior, J.; da Silva, N.B.; Ramos, A.P.M.; Moryia, É.A.S.; Imai, N.N.; Pereira, D.R.; Creste, J.E.; Matsubara, E.T.; et al. A convolutional neural network approach for counting and geolocating citrus-trees in UAV multispectral imagery. ISPRS J. Photogramm. Remote Sens. 2020, 160, 97-106. [CrossRef]

48. Astaoui, G.; Dadaiss, J.E.; Sebari, I.; Benmansour, S.; Mohamed, E. Mapping Wheat Dry Matter and Nitrogen Content Dynamics and Estimation of Wheat Yield Using UAV Multispectral Imagery Machine Learning and a Variety-Based Approach: Case Study of Morocco. AgriEngineering 2021, 3, 29-49. [CrossRef]

49. Mazzia, V.; Comba, L.; Khaliq, A.; Chiaberge, M.; Gay, P. UAV and machine learning based refinement of a satellite-driven vegetation index for precision agriculture. Sensors (Switzerland) 2020, 20, 2530. [CrossRef]

50. Ahmed, F.B. Estimation of leaf nitrogen and silicon using hyperspectral remote sensing. J. Appl. Remote Sens. 2010, 4, 043560. [CrossRef]

51. Laamrani, A.; Berg, A.A.; Voroney, P.; Feilhauer, H.; Blackburn, L.; March, M.; Dao, P.D.; He, Y.; Martin, R.C. Ensemble identification of spectral bands related to soil organic carbon levels over an agricultural field in southern Ontario, Canada. Remote Sens. 2019, 11, 1298. [CrossRef]

52. Hansen, P.M.; Schjoerring, J.K. Reflectance measurement of canopy biomass and nitrogen status in wheat crops using normalized difference vegetation indices and partial least squares regression. Remote Sens. Environ. 2003, 86, 542-553. [CrossRef]

53. Mistele, B.; Schmidhalter, U. Estimating the nitrogen nutrition index using spectral canopy reflectance measurements. Eur. J. Agron. 2008, 29, 184-190. [CrossRef]

54. Li, F.; Miao, Y.; Hennig, S.D.; Gnyp, M.L.; Chen, X.; Jia, L.; Bareth, G. Evaluating hyperspectral vegetation indices for estimating nitrogen concentration of winter wheat at different growth stages. Precis. Agric. 2010, 11, 335-357. [CrossRef]

55. Islam, K.; Singh, B.; McBratney, A. Simultaneous estimation of several soil properties by ultra-violet, visible, and near-infrared reflectance spectroscopy. Aust. J. Soil Res. 2003, 41, 1101-1114. [CrossRef]

56. César de Mello, D.; Alexandre Melo Demattê, J.; Alcantara de Oliveira Mello, F.; Roberto Poppiel, R.; ElizabetQuiñonez Silvero, N.; Lucas Safanelli, J.; Barros e Souza, A.; Augusto Di Loreto Di Raimo, L.; Rizzo, R.; Eduarda Bispo Resende, M.; et al. Applied gamma-ray spectrometry for evaluating tropical soil processes and attributes. Geoderma 2021, 381, 114736. [CrossRef]

57. Kuang, B.; Mahmood, H.S.; Quraishi, M.Z.; Hoogmoed, W.B.; Mouazen, A.M.; van Henten, E.J. Sensing soil properties in the laboratory, in situ, and on-line. A review. In Advances in Agronomy; Academic Press: New York, NY, USA, 2012; Volume 114, pp. 155-223. [CrossRef]

58. Abdel-Rahman, E.M.; Ahmed, F.B.; van den Berg, M. Estimation of sugarcane leaf nitrogen concentration using in situ spectroscopy. Int. J. Appl. Earth Obs. Geoinf. 2010, 12, S52-S57. [CrossRef]

59. Main, R.; Cho, M.A.; Mathieu, R.; O'Kennedy, M.M.; Ramoelo, A.; Koch, S. An investigation into robust spectral indices for leaf chlorophyll estimation. ISPRS J. Photogramm. Remote Sens. 2011, 66, 751-761. [CrossRef] 
60. Knox, N.M.; Skidmore, A.K.; Prins, H.H.; Heitkönig, I.M.; Slotow, R.; van der Waal, C.; de Boer, W.F. Remote sensing of forage nutrients: Combining ecological and spectral absorption feature data. ISPRS J. Photogramm. Remote Sens. 2012, 72, 27-35. [CrossRef]

61. Ramoelo, A.; Skidmore, A.K.; Cho, M.A.; Mathieu, R.; Heitkönig, I.M.; Dudeni-Tlhone, N.; Schlerf, M.; Prins, H.H. Non-linear partial least square regression increases the estimation accuracy of grass nitrogen and phosphorus using in situ hyperspectral and environmental data. ISPRS J. Photogramm. Remote Sens. 2013, 82, 27-40. [CrossRef]

62. Were, K.; Singh, B.R.; Dick, Ø.B. Spatially distributed modelling and mapping of soil organic carbon and total nitrogen stocks in the Eastern Mau Forest Reserve, Kenya. J. Geogr. Sci. 2016, 26, 102-124. [CrossRef]

63. Vergara-Díaz, O.; Zaman-Allah, M.A.; Masuka, B.; Hornero, A.; Zarco-Tejada, P.; Prasanna, B.M.; Cairns, J.E.; Araus, J.L. A novel remote sensing approach for prediction of maize yield under different conditions of nitrogen fertilization. Front. Plant Sci. 2016, 7, 666. [CrossRef] [PubMed]

64. Elsayed, S.; Elhoweity, M.; El-Hendawy, S.; Schmidhalter, U. Non-invasive spectral detection of the beneficial effects of Bradyrhizobium spp. And plant growth-promoting rhizobacteria under different levels of nitrogen application on the biomass, nitrogen status, and yield of peanut cultivars. Bragantia 2017, 76, 189-202. [CrossRef]

65. Kawamura, K.; Tsujimoto, Y.; Rabenarivo, M.; Asai, H.; Andriamananjara, A.; Rakotoson, T. Vis-NIR spectroscopy and PLS regression with waveband selection for estimating the total C and N of paddy soils in Madagascar. Remote Sens. 2017, 9, 1081. [CrossRef]

66. Chemura, A.; Mutanga, O.; Odindi, J.; Kutywayo, D. Mapping spatial variability of foliar nitrogen in coffee (Coffea arabica L.) plantations with multispectral Sentinel-2 MSI data. ISPRS J. Photogramm. Remote Sens. 2018, 138, 1-11. [CrossRef]

67. Gracia-Romero, A.; Kefauver, S.C.; Vergara-Díaz, O.; Zaman-Allah, M.A.; Prasanna, B.M.; Cairns, J.E.; Araus, J.L. Comparative performance of ground vs. Aerially assessed $\mathrm{rgb}$ and multispectral indices for early-growth evaluation of maize performance under phosphorus fertilization. Front. Plant Sci. 2017, 8, 2004. [CrossRef] [PubMed]

68. Ojoyi, M.M.; Mutanga, O.; Odindi, J.; Kahinda, J.M.M.; Abdel-Rahman, E.M. Implications of land use transitions on soil nitrogen in dynamic landscapes in Tanzania. Land Use Policy 2017, 64, 95-100. [CrossRef]

69. Yonah, I.B.; Mourice, S.K.; Tumbo, S.D.; Mbilinyi, B.P.; Dempewolf, J. Unmanned aerial vehicle-based remote sensing in monitoring smallholder, heterogeneous crop fields in Tanzania. Int. J. Remote Sens. 2018, 39, 5453-5471. [CrossRef]

70. Kawamura, K.; Tsujimoto, Y.; Nishigaki, T.; Andriamananjara, A.; Rabenarivo, M.; Asai, H.; Rakotoson, T.; Razafimbelo, T. Laboratory visible and near-infrared spectroscopy with genetic algorithm-based partial least squares regression for assessing the soil phosphorus content of upland and lowland rice fields in Madagascar. Remote Sens. 2019, 11, 506. [CrossRef]

71. Masemola, C.; Cho, M.A. Estimating leaf nitrogen concentration from similarities in fresh and dry leaf spectral bands using a model population analysis framework. Int. J. Remote Sens. 2019, 40, 6841-6860. [CrossRef]

72. Yousfi, S.; Gracia-Romero, A.; Kellas, N.; Kaddour, M.; Chadouli, A.; Karrou, M.; Araus, J.L.; Serret, M.D. Combined use of low-cost remote sensing techniques and $\delta 13 \mathrm{C}$ to assess bread wheat grain yield under different water and nitrogen conditions Agronomy 2019, 9, 285. [CrossRef]

73. Elmetwalli, A.H.; Tyler, A.N. Estimation of maize properties and differentiating moisture and nitrogen deficiency stress via ground-Based remotely sensed data. Agric. Water Manag. 2020, 242. [CrossRef]

74. Hengl, T.; Miller, M.A.; Križan, J.; Shepherd, K.D.; Sila, A.; Kilibarda, M.; Antonijević, O.; Glušica, L.; Dobermann, A.; Haefele, S.M.; et al. African soil properties and nutrients mapped at $30 \mathrm{~m}$ spatial resolution using two-scale ensemble machine learning. Technical Report 1. Sci. Rep. 2021, 11, 1-18. [CrossRef]

75. Peter, B.G.; Messina, J.P.; Carroll, J.W.; Chikowo, R. A case for green-based vegetation indices: Plot-scale sUAS imagery related to crop chlorophyll content on smallholder maize farms in Malawi. Remote Sens. Lett. 2021, 12, 778-787. [CrossRef]

76. Misbah, K.; Laamrani, A.; Chehbouni, A.; Dhiba, D.; Ezzahar, J. Use of Hyperspectral Prisma Level-1 Data and ISDA Soil Fertility Map for Soil Macronutrient Availability Quantification in a Moroccan Agricultural Land. In Proceedings of the 2021 IEEE International Geoscience and Remote Sensing Symposium IGARSS, Brussels, Belgium, 11-16 July 2021; pp. 7051-7054. [CrossRef]

77. Komolafe, A.A.; Olorunfemi, I.E.; Oloruntoba, C.; Akinluyi, F.O. Spatial prediction of soil nutrients from soil, topography and environmental attributes in the northern part of Ekiti State, Nigeria. Remote Sens. Appl. Soc. Environ. 2021, 21. [CrossRef]

78. Mariotto, I.; Thenkabail, P.S.; Huete, A.; Slonecker, E.T.; Platonov, A. Hyperspectral versus multispectral crop-productivity modeling and type discrimination for the HyspIRI mission. Remote Sens. Environ. 2013, 139, 291-305. [CrossRef]

79. Pierce, F.J.; Nowak, P. Aspects of Precision Agriculture. Adv. Agron. 1999, 67, 1-85. [CrossRef]

80. Gebbers, R.; Adamchuk, V.I. Precision agriculture and food security. Science 2010, 327, 828-831. [CrossRef] [PubMed]

81. Manfreda, S.; McCabe, M.F.; Miller, P.E.; Lucas, R.; Madrigal, V.P.; Mallinis, G.; Dor, E.B.; Helman, D.; Estes, L.; Ciraolo, G.; et al. On the use of unmanned aerial systems for environmental monitoring. Remote Sens. 2018, 10, 641. [CrossRef]

82. Mponela, P.; Snapp, S.; Villamor, G.B.; Tamene, L.; Le, Q.B.; Borgemeister, C. Digital soil mapping of nitrogen, phosphorus, potassium, organic carbon and their crop response thresholds in smallholder managed escarpments of Malawi. Appl. Geogr. 2020, 124, 102299. [CrossRef]

83. Hengl, T.; Leenaars, J.G.; Shepherd, K.D.; Walsh, M.G.; Heuvelink, G.B.; Mamo, T.; Tilahun, H.; Berkhout, E.; Cooper, M.; Fegraus, E.; et al. Soil nutrient maps of Sub-Saharan Africa: Assessment of soil nutrient content at $250 \mathrm{~m}$ spatial resolution using machine learning. Nutr. Cycl. Agroecosystems 2017, 109, 77-102. [CrossRef] 